\title{
JOURNAL
}

\author{
OF THE
}

\section{AMERICAN CERAMIC SOCIETY}

A monthly Journal devoted to the arts and sciences related to the silicate industries.

Editor: E. W. WASHBURN; Associate Editors: L. E. BARRINGER, A. V. BLEINinger, R. L. Clare, E. P. Poste, H. Ries, F. H. Rhead, R. B. Sosman, R. T. Stuli, E. W. TrLlotson

\section{Vol. 4}

\section{EDITORIAL}

\section{THE EXECUTIVE CONFERENCE}

The Executive Conference held at the Hotel Commodore, New York City, Sept. 15th and 17th, was attended by approximately fifty past or present officers, members of committees, etc.

The discussion covered an outline of topics that was prepared by the Organizing Secretary, Mr. Purdy, constituting a survey of the problems pertaining to the Society as a whole, and more particularly those pertaining to the efficient functioning of the Sections and Divisions.

As a result of the discussions, certain changes in the constitution and in the by-laws were proposed, which were read at the regular meeting of the Society, held on Sept. 16th, Ceramic Day, at the Chemical Exposition. These will be submitted to the membership for vote.

Further, a number of recommendations were made to the board of trustees for their consideration and action. The results of the final action on the various proposals and recommendations will be published as soon as the vote has been completed, which should be at an early date.

It is beyond question that the Society is on the threshold of a greatly extended program in accordance with its original and reaffirmed purpose, viz., "To advance the ceramic arts and 
sciences." In the interpretation of this purpose a closer contact with the ceramic manufacturer is being developed. In its finality, the activities of the Society redound to the economic benefit of the manufacturer in particular and to the economic and aesthetic benefit of humanity in general.

This program of larger service will naturally require more money. The board of trustees has inaugurated the agencies of this service with the conviction that all ceramic entities, industrial associations, corporations, and individuals, will be pleased to contribute proportionately to the financing of the project and will be assured that every dollar so invested has been most advantageously placed.

It is the duty and personal privilege of each member of the Society to give his quota of the larger service and to help solicit the needed financial support.

\section{F. K. Pence.}

\section{TO AUTHORS OF PAPERS}

Authors' manuscripts and original drawings are preserved in this office for twelve months following date of publication, after which they are destroyed. Authors desiring any of this material returned to them should notify the Editor's office within the twelve month period. 